Article

\title{
In Vitro DVS Approach to Evaluate Skin Reparation
}

\author{
Clara Barba ${ }^{1, *}$, Cristina Alonso ${ }^{1}$, Alessandra Semenzato ${ }^{2}$, Giovanni Baratto ${ }^{3}$ and \\ Luisa Coderch 1 \\ 1 IQAC-CSIC, Jordi Girona 18-26, 08034 Barcelona, Spain; camesl@iqac.csic.es (C.A.); lcnesl@iqac.csic.es (L.C.) \\ 2 Department of Pharmaceutical and Pharmacological Sciences, University of Padova, Via F. Marzolo 5, \\ 35231 Padova, Italy; semenzatoalessandra76@gmail.com \\ 3 Unifarco S.p.A., Via Cal Longa 62, 32035 Santa Giustina (BL), Italy; gianni.baratto@unifarco.it \\ * Correspondence: cbaesl@iqac.csic.es; Tel.: +34-93-400-61-79
}

Academic Editor: Marie Lodén

Received: 10 December 2015; Accepted: 18 March 2016; Published: 31 March 2016

\begin{abstract}
The stratum corneum (SC), the most superficial layer of the skin, is directly responsible for the skin's barrier function. The intercellular lipids in the SC play an important role in the regulation of the skin's water-holding capacity. The modification of the intercellular lipid organization and composition may impair these properties. The aim of the present study is to describe a new in vitro approach of the repairing capacity evaluation of lipid formulations on skin with the use of absorption and desorption curves. The formulations were applied on lipid-extracted SC, and the possible SC reparation was assessed with the use of a thermogravimetric balance (DVS). Moisture absorption/desorption experiments proved to be adequate for the evaluation of the repairing capacity of formulations applied on damaged skin. Besides, freeze-substitution transmission electron microscopy (FSTEM) images showed some lipid bilayers, indicating a lipid bilayer reconstitution due to the applied formulations.
\end{abstract}

Keywords: stratum corneum; lipids; thermogravimetric analysis; permeability; water diffusion

\section{Introduction}

The skin barrier function is located in the stratum corneum (SC), where the majority of the limited transport of substances occurs between the corneocytes in the lipid bilayers [1,2]. The lipid bilayers are composed of ceramides, cholesterol and free fatty acids. In particular, the ceramide profile relates to the barrier function of the skin [3]. They consist of sphingoid bases, which are amide-linked to $\alpha$-hydroxylated, $\omega$-hydroxylated or non-hydroxylated fatty acids. Separation on high-performance thin-layer chromatography (HPTLC) plates showed seven ceramide classes [4]. However, in contrast with cellular membranes, ceramides located in the intercellular spaces are not able to form bilayers configurations by themselves [5].

Although the intercellular epidermal lipids only account for approximately $15 \%$ of the SC weight (with the remainder being $15 \%$ water and $70 \%$ proteins), they are essential components of a suitable barrier function and prevent (in combination with the so-called hydrolipidic layer) excessive transepidermal water loss [6-9]. In terms of total lipid mass, the human SC is approximately $50 \%$ ceramides, $25 \%$ cholesterol, and $15 \%$ free fatty acids. The modification of the SC lipid organization or composition has been shown to impair the skin properties. In particular, a reduction of free fatty acids (FFA chain length results in phase separation and an increased SC permeability [10]. In other studies ceramides (CER) acyl chain length were also related to SC permeability [11,12]. When SC lipids are modified the skin loses water and becomes dry, cracked and fissured, and allows the entrance of allergens, toxins and microorganisms that can inflame and irritate the skin [13]. Numerous findings have shown that there is a marked depletion of SC lipids in patients with some skin diseases such as psoriasis, atopic dermatitis (AD), ichthyosis and xerosis [14-16]. This diminished skin barrier function 
on the skin diseases mentioned has been related to an overall decrease in total SC lipids [17-19] and, in particular, to a decrease in ceramides [20-22]. Skin barrier disruption caused by a topical treatment with organic solvents, surfactants or the removing of successive layers of corneocytes by tape stripping, is attributed to a selective/integral depletion or an alteration of the intercellular lipids organization $[23,24]$. Recent studies have suggested that supplementing intercellular lipids of SC with formulations containing lipids that resemble the natural components of the skin can stimulate skin function [23,25-27]. Furthermore, most skin disorders with a diminished barrier function present a decrease in total ceramide content with some differences in the ceramide pattern [3].

In contrast to traditional emollients that form an external occlusive barrier due to the presence of petrolatum or other mineral oils, physiological lipid-based topical emulsions are supposed to permeate the SC and stimulate the endogenous lipid synthesis, particularly ceramides, leading to, over a long period treatment, an increase in the total amount of epidermal mortar. Because of this peculiar mechanism of action, these cosmetic emollients are usually called barrier repair topical emulsions $[27,28]$. The helpfulness of cosmetic emollients in the management of pathological skin is commonly evaluated in vivo using non-invasive biophysical techniques (transepidermal water loss (TEWL) and skin hydration), before and after the treatment $[25,26]$. These in vivo tests allow for the quantification of the final clinical effects of emollients, but they are not able to discriminate how the product interacts with the skin, with respect to its peculiar formulative features.

Several studies have been carried out to determine the role of the lipids in the water permeability of keratinized tissues such as SC and hair. It is well known that changes in SC lipid composition may be one of the underlying factors responsible for a reduced skin barrier function. Previous studies demonstrated that changes in SC lipid composition result in differences in SC permeability. In particular, structural lipid changes, lipid chains' length and/or unsaturations, play a crucial role in SC barrier function permeability [29-31]. Studies using a synthetic model lipid membrane to evaluate the SC lipid permeability have been recently carried out [31]. Furthermore, techniques such as differential scanning calorimetry (DSC) and flux of tritiated water vapor have been used to study the SC water permeability [32]. Besides, techniques such as a thermal desorption autosampler coupled to a mass spectrometer have also been used to measure the in vitro water retention of human SC as a function of a treatment applied [33].

The determination of the water sorption isotherm by isothermally applying discrete, cumulative humidity changes involves dynamic and static aspects from which the diffusion coefficients and the equilibrium water contents are deduced [34]. Time/absorption isotherms provide a complete description of the absorption phenomenon under particular conditions such as the initial regain of the sample, temperature and relative humidity [35]. The moisture sorption isotherm of keratins has been the subject of several studies and models have been specially developed for describing the shape of the moisture sorption and desorption.

The aim of this study is to describe a new in vitro approach to evaluate the repairing effect capacity of three lipid mixtures, including ceramides, on the SC barrier function: CEM, the lipid mixture solubilized in the oily phase of oil in water emulsion; MIC, the lipid mixture dispersed as solid microparticles in a gel formulation; and IWL, the lipid mixture as liposome solution. For that purpose, the formulations were applied on lipid-extracted SC and the possible SC reparation was assessed with the use of a thermogravimetric balance (DVS) and freeze-substitution transmission electron microscopy (FSTEM) images.

\section{Methodology}

\subsection{Chemicals}

Cholesterol sulfate was provided by Sigma (St. Louis, MO, USA). Chloroform, methanol and 99.0\% sodium chloride $(\mathrm{NaCl})$ were supplied by Merck (Darmstadt, Germany). Phosphate-buffered 
saline (PBS) and trypsin (from porcine pancreas) were obtained from Sigma-Aldrich. Purified water was obtained by an ultra-pure water system (Milli-Q plus 185, Millipore, Bedford, MA, USA).

The chemicals for preparing microscopy samples were ruthenium tetroxide $\left(\mathrm{RuO}_{4}\right)$, lowicryl HM20, glutaraldehyde, sodium cacodylate buffer (Electron Microscopy Sciences, Hatfield, PA, USA), methanol, potassium ferrocyanide $\left(\mathrm{K}_{4} \mathrm{Fe}(\mathrm{CN})_{6}\right)$ (Merck), and osmium tetroxide $\left(\mathrm{OsO}_{4}\right)$ (Pelco International, Redding, CA, USA).

\subsection{Lipid Formulations}

Liposomes were prepared with $0.5 \%$ internal wool lipids (IWL), which mainly consist of mixture of cholesterol-esters $(4 \%)$, free fatty acids $(27 \%)$, cholesterol $(19 \%)$, glycosylceramides $(12 \%)$, cholesterol sulfate $(10 \%)$ and ceramides $(29 \%)$ obtained by extraction at the pilot level [36]. IWL liposomes were prepared by dissolving the IWL in chloroform/methanol 2:1 $(v / v)$ and evaporating to dryness under a stream of dry nitrogen to form a thin film on the flask. The film was hydrated with $0.9 \% \mathrm{NaCl}$ solution to give a final suspension that contained $0.5 \%$ liposomes. Multilamellar vesicle liposomes were formed by the sonication of the suspension in a sonicator, Labsonic 1510 (Braun, Melsungen, Germany), at $100 \mathrm{~W}$ for about $15 \mathrm{~min}$, maintaining the temperature at $65^{\circ} \mathrm{C}$.

The ceramide emulsion (CEM) was supplied by Unifarco (Santa Giustina, Italy). It is a cream based on a non-ionic emulsifier that possesses high affinity and compatibility with skin. It is a commercial oil in a water emulsion containing hydrocarbons and triglycerides as oily phase ( $4 \%$ short chain triglycerides and 5\% aliphatic hydrocarbons) and a physiological lipid mixture (ceramide 3, cholesterol, fatty acids) directly solubilised in the oily phase as barrier repair ingredients.

Microceramides (MIC), solid lipid microparticles, obtained from an ethanolic solution of ceramide 3, cholesterol, fatty acid (1:1.1) by spray drying technique [37], dispersed at $0.5 \%$ in a gel formulation.

While the IWL liposomes and the microceramides have around $0.15 \%$ ceramides, the ceramide emulsion has a higher amount of ceramides, about $0.40 \%$. These differences will have to be taken into consideration with the results obtained.

\subsection{Isolation of $S C$}

The management of the Landrace Large White pigs used in this study conforms to the Guide for the Care and Use of Laboratory Animals published by the United States National Institutes of Health [38].

Sections of fresh skin from young pigs, weighing $20-30 \mathrm{~kg}$, were placed in water at $70{ }^{\circ} \mathrm{C}$ for 3-4 min; the epidermis was scrapped off in sheets. To isolate the SC, the epidermal sheets were incubated for $2 \mathrm{~h}$ at $37^{\circ} \mathrm{C}$ with the epidermal side in contact with a solution of $0.5 \%$ trypsin in PBS at $\mathrm{pH}$ 7.4. Trypsin is used to remove adherent cells from epidermis. After the $2 \mathrm{~h}$, the trypsin was removed by several washes of the SC with Milli-Q water [39].

\subsection{Lipid Extraction of SC}

SC Lipid extraction was done with an organic solvent system, chloroform/methanol (2:1), over $2 \mathrm{~h}$ and immediately washed with water for $15 \mathrm{~min}$ with constant agitation (lipid extracted stratum corneum, LE SC) [40].

\subsection{SC Treatments}

The lipid-extracted SC (LE SC) was treated with the lipid formulations. Thus, $100 \mathrm{mg}$ of the LE SC tissue was immersed in $100 \mathrm{mg}$ of the each lipid formulation at $25^{\circ} \mathrm{C}$ for $48 \mathrm{~h}$, and then removed from the ceramide containing samples and immediately washed with water for 15 min with constant agitation. The lipid-extracted SC samples treated with the different lipid formulation (LE SC CEM, LE SC IWL and LE SC MIC) were then stored at dryness. The control samples (untreated stratum 
corneum, non-treated (NT) SC and lipid extracted, LE SC) were incubated in water alone for 15 min and also stored at dryness.

\subsection{Sorption Experiments}

Absorption and desorption curves were obtained in a thermogravimetric balance equipped with a controlled humidity chamber, the Q5000SA Sorption Analyzer (TA Instruments, New Castle, DE, USA). The weight of the SC samples analyzed ranged between 3 and $5 \mathrm{mg}$. Before measuring the sorption properties, the SC samples were kept under humidity controlled conditions $\left(22{ }^{\circ} \mathrm{C}\right.$ and $65 \%$ relative humidity $(\mathrm{RH})$ ) for $48 \mathrm{~h}$. All experiments were conducted at $25{ }^{\circ} \mathrm{C}$ with a total gas flow of $200 \mathrm{~mL} / \mathrm{min}$ and followed the same measuring procedure:

1. Pre stabilization: temperature $25{ }^{\circ} \mathrm{C}, 0 \%$ relative humidity $(\mathrm{RH})$ overnight. The sample remains in this step until its mass reaches equilibrium (arbitrarily defined by a change in mass of less than $0.02 \%$ per minute for $20 \mathrm{~min}$ ).

2. Absorption curve: initial absorption kinetics at $5 \% \mathrm{RH}$, then the sample previously stabilized at $5 \% \mathrm{RH}$ is subjected to absorption tests, progressively increasing in steps from $30 \%$ up to $95 \%$, and the sample being stabilized at 95\% RH after the last step. The sample remains in each step until its mass reaches equilibrium (arbitrarily defined by a change in mass of less than $0.02 \%$ per minute for $20 \mathrm{~min}$ ).

3. Desorption curve: the sample that was stabilized at $95 \% \mathrm{RH}$ after the absorption process kinetics is subjected to desorption tests progressively decreasing in steps from $30 \%$ down to $5 \%$, with the sample stabilized at 5\% RH after the last step. The sample remains in each stage until its mass reaches equilibrium (arbitrarily defined by a change in mass of less than $0.02 \%$ per minute for $20 \mathrm{~min})$.

The high reproducibility of these measurements was established in the validation study of this instrument in which three replicates of a single sample gave essential coincident sorption isotherms. For this reason, and given the long time needed for a measurement (three days), only one measurement was performed for each sample.

In this work, sorption isotherm data were modelled according to the Guggenheim-Anderson-de Boer (GAB) model in line with other authors [35,41,42]. Table 1 shows the sorption isotherm and the parameters used to fit the experimental sorption/desorption data [43]. The goodness of the fit was evaluated by the determination coefficient $\left(R^{2}\right)$.

Table 1. Guggenheim-Anderson-de Boer (GAB) model and parameters used to fit the experimental sorption data.

\begin{tabular}{ll}
\hline Model & Mathematical Equation \\
\hline GAB [43] & $W=W_{m} \cdot C_{g} \cdot K \cdot a_{w} /\left[\left(1-K a_{\mathrm{w}}+C_{g} \cdot K \cdot a_{w}\right)\right]$ \\
\hline$a_{w}$ & Definition \\
\hline$W$ & $\begin{array}{l}\text { Water activity expressed as the relative vapor pressure, } p / p 0, \text { where } p 0 \text { is the } \\
\text { saturated vapor pressure. }\end{array}$ \\
\hline$W_{m}$ & Equilibrium moisture content at $a_{w}$ in $g$ sorbed $/ 100 \mathrm{~g}$ of sorbent on a dry basis. \\
\hline$C_{g}$ & Monolayer moisture content in $g$ sorbed $/ 100 \mathrm{~g}$ of sorbent on a dry basis (d.b.) \\
\hline$K$ & $\begin{array}{l}\text { Energy constant related to the difference between the free enthalpies of the water } \\
\text { molecules in the pure liquid state and in the monolayer. This constant is } \\
\text { proportional to the rate between both the attachment and the escape rate } \\
\text { constants of the primary sites. }\end{array}$ \\
\hline & $\begin{array}{l}\text { Ratio between of the standard vapor pressure of the liquid and the vapor pressure } \\
\text { of the sorbate in the secondary (upper) layers. This ratio is proportional to the } \\
\text { rate between the attachment and the escape rate constant for all higher layers. }\end{array}$ \\
\hline
\end{tabular}

Moisture sorption/desorption tests on hygroscopic samples take a very long time to reach equilibrium, although the most important interchange of water occurs in the initial steps. Therefore, some conditions are fixed to shorten the testing time. Although at this point the regain at the 
equilibrium was not reached, the regain at the equilibrium $R \propto$ could be calculated by fitting the appropriate model. Therefore, the absorption/desorption curves of each step were fitted to the following kinetic model [29]:

$$
R(t)=\frac{B t^{C}}{A^{C}+t^{C}}
$$

$R(t)$ is the regain of the sample at time $t, B$ the regain at the equilibrium $(R \infty)$, $A$ coincides with the time of half absorption $\left(t_{1 / 2}\right)$ and $c$ is a power coefficient of each step.

The application of the non-linear regression procedures obtained the best estimates of the model parameters yielding $B, A$ and $c$, which enabled us to calculate the asymptotic regain at equilibrium $R \infty$ and the half absorption time $t_{1 / 2}$ and rate $v_{1 / 2}$. The non-linear regression required unbiased initial estimators of the model parameters that were provided by the linear regression between $t / R(t)$ and $t$ through the straight line $t / R(t)=\alpha+\beta t$, where $\alpha / \beta$ and $1 / \beta$ were, respectively, the initial estimators of $A$ and $B$ [35].

The diffusion coefficient was obtained using the method applied by Vickerstaff [44] to study the diffusion of dyes within the fibers. It appears that the diffusion is well fitted by an expression derived from Fick's equation applied to moisture diffusion. This expression yielded satisfactory results in the early stages of moisture absorption as in the case of those obtained in dye diffusion. If the fractional absorbed moisture is plotted against the square root of the absorption time, the points should lie on a straight line:

$$
R(t) / R \infty=\sqrt{D_{A}} \sqrt{t}
$$

The slope is considered to be the square root of the apparent diffusion coefficient $D_{A}$ of the moisture. If the apparent diffusion coefficient is measured over sample mass instead of over sample surface, it is measured in $\min ^{-1}$.

\subsection{Freeze-Substitution Transmission Electron Microscopy Experiments (FSTEM)}

The SC samples were fixed in 5\% glutaraldehyde in a $0.1 \mathrm{M}$ sodium cacodylate buffer, $\mathrm{pH} 7.3$, and postfixed in $0.25 \% \mathrm{RuO}_{4}$ in $0.1 \mathrm{M}$ sodium cacodylate, $\mathrm{pH} 6.8$, with $0.25 \%$ potassium ferrocyanide $\left(\mathrm{K}_{4} \mathrm{Fe}(\mathrm{CN})_{6}\right)$. After $1 \mathrm{~h}$ the $\mathrm{RuO}_{4}$ solution was replaced by fresh $\mathrm{RuO}_{4}$ in order to establish an optimal fixation. After rising in buffer, the SC samples were cryofixed, by rapid freezing on a liquid nitrogen-cooled metal mirror (Cryo-vacublock, Leica, Wetzlar, Germany) at $-196{ }^{\circ} \mathrm{C}$ prior to freeze-substitution.

The freeze-substitution procedure was carried out in an AFS (Automatic Freeze Substitution) system (Leica). The tissue samples were cryosubstituted at $-90{ }^{\circ} \mathrm{C}$ for $48 \mathrm{~h}$ using $100 \%$ methanol, containing $1.0 \%(w / v)$ osmium tetroxide $\left(\mathrm{OsO}_{4}\right), 0.5 \%(w / v)$ uranyl acetate and $3.0 \%(w / v)$ glutaraldehyde. After the $48 \mathrm{~h}$ substitution period, the temperature was raised to $-50{ }^{\circ} \mathrm{C}$, the samples were washed three times in $100 \%$ methanol, and subsequently the methanol solution was gradually replaced by the embedding medium, Lowicryl HM20 (100\%). This resin was replaced after 24 and $48 \mathrm{~h}$ with a freshly made bedding medium. Finally, the samples were transferred to a mold containing Lowicryl, and were incubated for $8 \mathrm{~h}$ at $-50{ }^{\circ} \mathrm{C}$ under UVA radiation to allow for polymerization. Ultrathin sections were cut (Ultracut UCT, Leica) and examined in a Hitachi 600 transmission electron microscope $[45,46]$.

\section{Results}

The SC was isolated from fresh pigs' backs and was treated with organic solvents in order to extract the SC lipids according to the procedure described in the previous section (LE SC). In an earlier study, the effect of the lipid extraction from the SC sample was demonstrated [42]. When the lipids were extracted, there was a clear decrease in the SC water content. This decreased capacity to absorb water was observed for the LE SC at all the humidity steps evaluated. Furthermore, when the SC 
was damaged by the treatment with the organic solvents there was a significant increase in the SC's permeability, as demonstrated by a substantial increase in the values of the diffusions coefficients [40].

To study the possible repairing effect of the tested formulations with the use of the DVS methodology, the ceramide samples were applied on the lipid extracted SC (LE SC). Water sorption and desorption isotherms for all the SC samples were evaluated by the software provided by the TA instrument. The moistures contents were plotted against the relative humidity to create the isotherms and are shown in Figures 1 and 2. The most remarkable difference between the non-treated sample (NT SC) and the lipid extracted sample (LE SC) is the clear reduction of its water content (Figure 1 and Table 2). When the lipids are extracted from the SC the resultant tissue has a lower capacity to absorb water. These results demonstrate the important role of the SC lipids on maintaining an adequate skin water balance. It is well known that depleting the SC lipids disrupts the skin's barrier function by altering the intercellular lipids bilayers, which reduces the water retention characteristics of the SC. However, when the lipids samples were applied on the delipidized SC the obtained results showed that the decrease in water content due to the SC delipidization was not re-established due to the ceramide formulation applications.

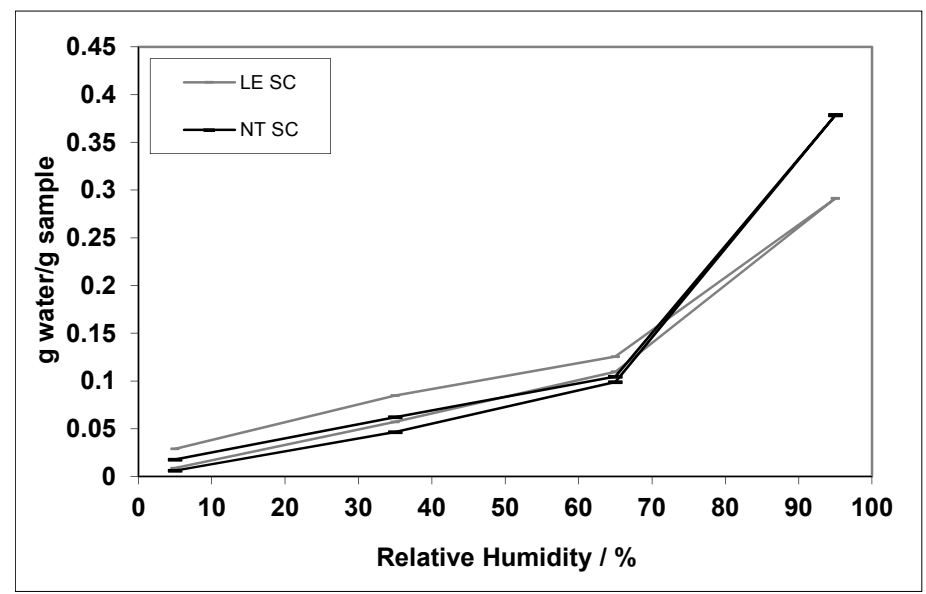

Figure 1. Water sorption isotherms for non-treated SC (NT SC) and lipid-extracted SC (LE SC).

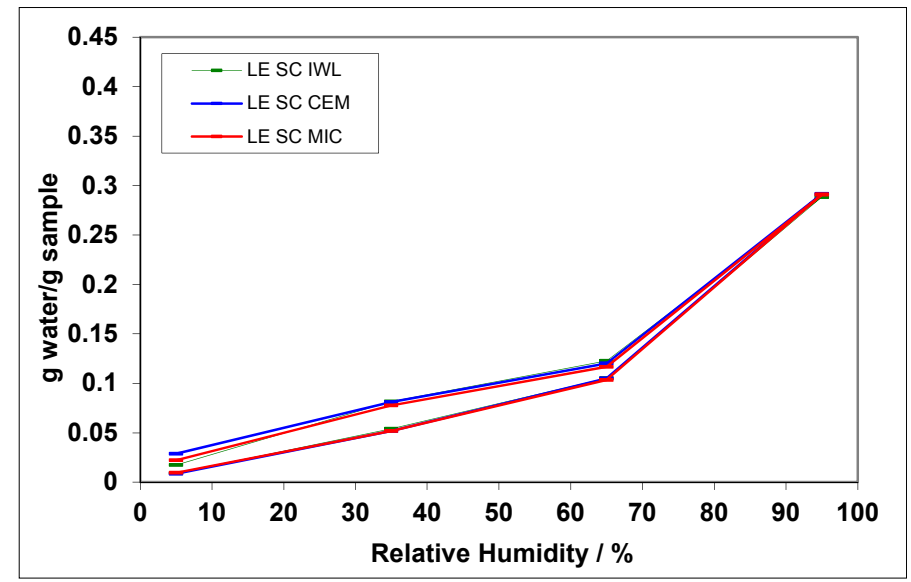

Figure 2. Water sorption isotherms for lipid-extracted stratum corneum (SC) treated with the ceramide containing samples (internal wool lipids, LE SC IWL; ceramide emulsion, LE SC CEM; and microceramides, LE SC MIC). 
Table 2. Maximum moisture regain, GAB monolayer capacity $\left(W_{m}\right)$, GAB energy constants $\left(C_{g}\right.$ and $K), \mathrm{GAB}$ determination coefficient $\left(R^{2}\right)$, total time to reach equilibrium $\left(t_{T}\right)$, apparent diffusion coefficient $\left(D_{A}\right)$ and apparent diffusion coefficient on the desorption $\left(D_{A d}\right)$ for non-treated SC (NT SC), lipid-extracted SC (LE SC) and lipid-extracted SC treated with the ceramide containing samples (LE SC CEM, LE SC IWL and LE SC MIC).

\begin{tabular}{ccccccccc}
\hline SC Samples & Regain at 95\%RH (\%) & $W m$ & $C_{g}$ & $K$ & $R^{\mathbf{2}}$ & $\boldsymbol{t}_{\boldsymbol{T}}(\mathbf{m i n})$ & $\boldsymbol{D}_{A}\left(\mathbf{m i n}^{-\mathbf{1}}\right)$ & $\boldsymbol{D}_{A d}\left(\mathbf{m i n}^{-\mathbf{1}}\right)$ \\
\hline NT SC & 37.88 & 0.048 & 3.581 & 0.902 & 0.999 & 3780.42 & $0.0214 \pm 0.015$ & $0.0208 \pm 0.017$ \\
LE SC & 29.12 & 0.073 & 3.937 & 0.741 & 0.999 & 2260.75 & $0.0396 \pm 0.024$ & $0.0453 \pm 0.032$ \\
LE SC IWL & 28.83 & 0.060 & 4.639 & 0.809 & 0.999 & 3480.82 & $0.0257 \pm 0.017$ & $0.0274 \pm 0.012$ \\
LE SC CEM & 29.16 & 0.062 & 3.972 & 0.801 & 0.999 & 3500.79 & $0.0250 \pm 0.014$ & $0.0277 \pm 0.013$ \\
LE SC MIC & 29.10 & 0.055 & 5.009 & 0.829 & 0.999 & 3160.78 & $0.0361 \pm 0.021$ & $0.0348 \pm 0.014$ \\
\hline
\end{tabular}

Sorption isotherms are generally described by mathematical models based on empirical and/or theoretical criteria that can be found in the literature. One of the most commonly used equations is the Guggenheim-Anderson-de Boer (GAB) model. This model has a theoretical background, and its parameters have physical meaning in the sorption process, in contrast to the parameters of empirical models. The GAB model is based on the monolayer moisture concept and gives the value of the monolayer moisture content of the material [47]. The GAB model has proven to be applicable to hydrophilic polymers [48,49] and food systems [50] and has considerable theoretical justification [51]. The regression of the experimental sorption data using the GAB model yields the values of $W_{m}$, the monolayer capacity, and $\mathrm{Cg}$ and $\mathrm{K}$, the energy constants [39] (Table 2).

A good fit of the uptake and desorption data to the GAB model was achieved for all samples $\left(R^{2}>0.997\right)$. When the lipids were extracted from the SC an increase in the monolayer capacity $\left(W_{m}\right)$ was observed, which indicated that water molecules could penetrate more easily through the primary layers of the damaged tissue. In addition, the LE SC showed an increase in the $C g$ and a decrease of $K$, both energy constants. These results indicated a possible increase in the binding energy of water to the active groups of the primary layers of the tissue, which most likely became more polar and, furthermore, that water could be more easily released from the damaged SC as evidenced by a decrease of the energy constant for higher layers.

Moreover, when the ceramide formulations were applied on the LE SC, the resultant tissues showed a decrease in the monolayer capacity value. This decrease in $W_{m}$ can be attributed to the presence of the applied lipids on the primary layers of the SC, which gives rise to a reduction of its polar behavior with a reduction of the monolayer capacity. Furthermore, the ceramide formulations application led to tissues with higher values of both energy constants, $C g$ and $K$. The increase in the energy constants demonstrates that the LE CS-treated samples have improved their ability to bind the water molecules in both primary and higher tissues layers due to the ceramide formulations application. However, these results are not significant due to the fact that in this study the GAB model was fit to data from only four RH steps.

The moisture diffusion kinetics through the SC tissues were also evaluated and the apparent diffusion coefficients $\left(D_{A}\right)$, the time of half absorption/desorption $\left(t_{1 / 2}\right)$ and the total time $\left(t_{T}\right)$ have been calculated as detailed in the experimental section for each humidity step. The mean values are summarized in Table 2. The diffusion coefficients, which are related to the water permeability, are useful to determine the integrity of keratinized tissue [52]. In general, when the integrity of a certain sample has deteriorated, an increase in the water permeability is observed, with an increase in the diffusion coefficients. Moreover, it was also observed that there is a decrease in the time needed for the sample to reach equilibrium. The lipid extraction from the SC showed a clear increase in the diffusion coefficient of the resultant sample (Table 2), indicating an increase in the water permeability through the LE SC tissue. Furthermore, there was also a clear decrease in the times needed to reach equilibrium for the LE SC, which is maintained in each humidity step, thus demonstrating the deterioration of the resulting SC sample (Table 2). During desorption, the sample is initially saturated $(95 \% \mathrm{RH})$ and the evaluation of the water release can be more realistic and more directly associated with the sample structure. For this reason, the apparent diffusion coefficient during only the desorption process 
$\left(D_{A d}\right)$ has been also calculated (Table 2). Results showed that the effect of the lipid extraction is more pronounced with a bigger increase in the $D_{A d}$ for the extracted SC sample. These results are in accordance with a previous study were an in vivo method that uses skin occlusion was correlated with some functional parameter of the skin. In particular, the desorption of the occluded skin water loss, measured by means of transepidermal water loss, was related with the state of the skin barrier function [53].

The evaluation of the times needed to reach equilibrium demonstrates that when the ceramide formulations were applied on the damaged SC, the resultant tissues needed more time to reach equilibrium; this was observed for all the lipid formulations applied (Table 2). Furthermore, this increase in the times to reach equilibrium was kept in the majority of the humidity steps evaluated, being more clear for the IWL liposomes and the ceramides emulsion application (Figure 3). In addition, the results showed a clear decrease in the mean value of the apparent diffusion coefficient when the ceramide emulsion and the IWL liposomes were applied on LE SC (Table 2). The evaluation of the diffusion coefficients in the different humidity steps showed that all three lipid samples induced a recuperation of the diffusions coefficients values in most of the humidity steps evaluated, which were previously increased due to the lipid extraction (Figure 4). These results were also clearer for the ceramide emulsion and the IWL liposomes. Again, the results considering only the desorption process are more clear (Table 2). The high increase in the diffusion coefficient due to lipid extraction is clearly decreased when applying the ceramides formulations.

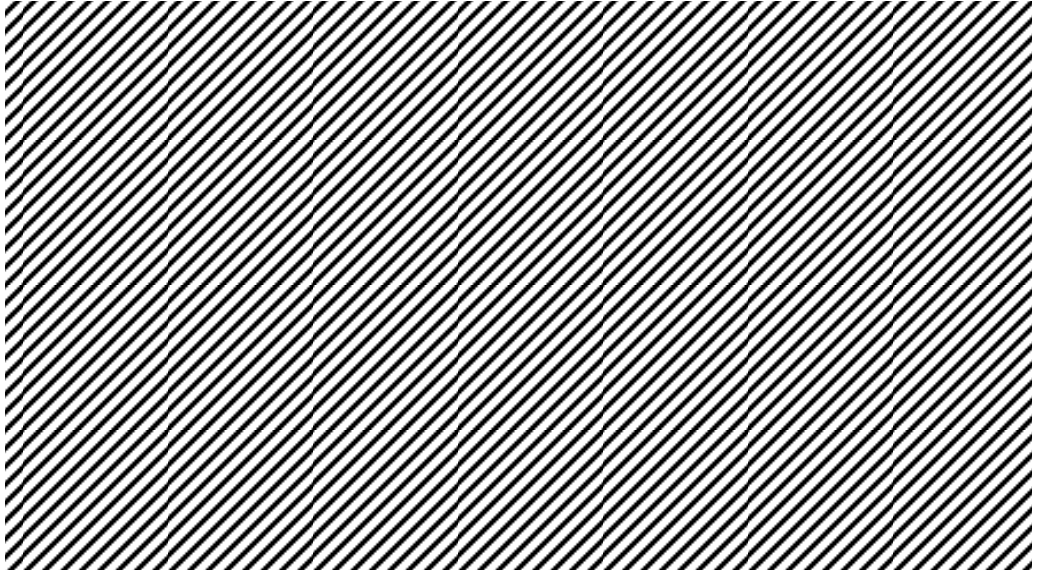

Figure 3. Time of half absorption/desorption for lipid-extracted SC (LE SC) and lipid-extracted SC treated with the ceramide containing samples (LE SC CEM, LE SC IWL and LE SC MIC).

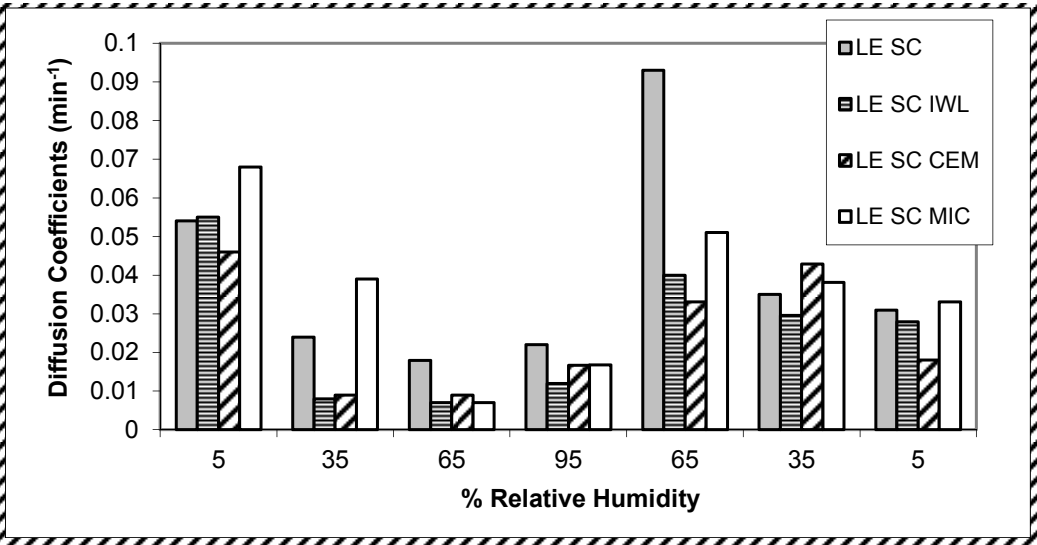

Figure 4. Diffusion coefficients for lipid-extracted SC (LE SC) and lipid-extracted SC treated with the lipid formulations (LE SC CEM, LE SC IWL and LE SC MIC). 
To reinforce the described results, FSTEM micrographs of all the SC samples were obtained following the methodology described in the experimental section. As found previously by other authors [54], the FSTEM methodology enabled a good visualization of the untreated and treated SC. A good visualization of the lipid bilayers on the non-treated SC sample (Figure 5a) was found. Moreover, when the SC was submitted to a solvent lipid extraction procedure, the resultant tissue showed complete absence of lipid bilayers (Figure 5b). As stated by other authors [55] chloroform-methanol mixtures were able to remove mainly the lipid without a significant loss of cohesion in the SC tissue. The effect of lipid on SC has been studied by a number of authors [56-58]. In these works, different structural SC changes that disturb the intercellular lipids organization have been reported, i.e., formation of water pools and vesicles, deposition of individual molecules, etc.
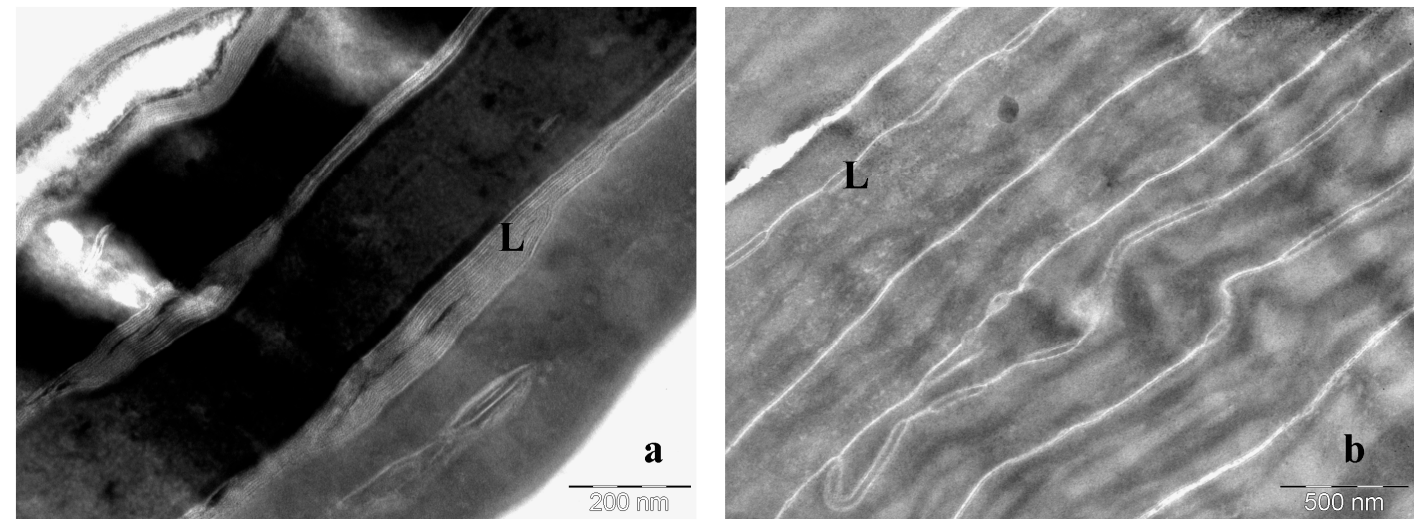

Figure 5. Freeze-substitution transmission electron microscopy (FSTEM) micrographs for SC (a) non-treated (NT) and (b) delipidized (LE SC) (L indicates the lipid region).

Furthermore, it was also established that the liposomes formed with lipids from the SC-induced modifications when applied to delipidized SC, and these modifications could be associated with a restoration of the damaged intercellular lipid structure [59]. In our study, FSTEM images showed that when the lipid formulations were applied on the delipidized SC sample (LE SC), some lipid bilayers appeared. These results could indicate a possible mechanism of re-assembly of the applied lipid molecules with the lipids remaining in the SC. This re-assembly could be associated with the possible restoration of the damaged SC lipid structures by the action of the treatments with the lipids formulations. More amounts of reconstituted bilayers were found when the LE SC was treated with the ceramide emulsion and the liposome formulation (Figure 6a,b). These results are in concordance with the DVS results where a higher improvement on the water permeability due to the ceramide emulsion and the liposome formulation was demonstrated.
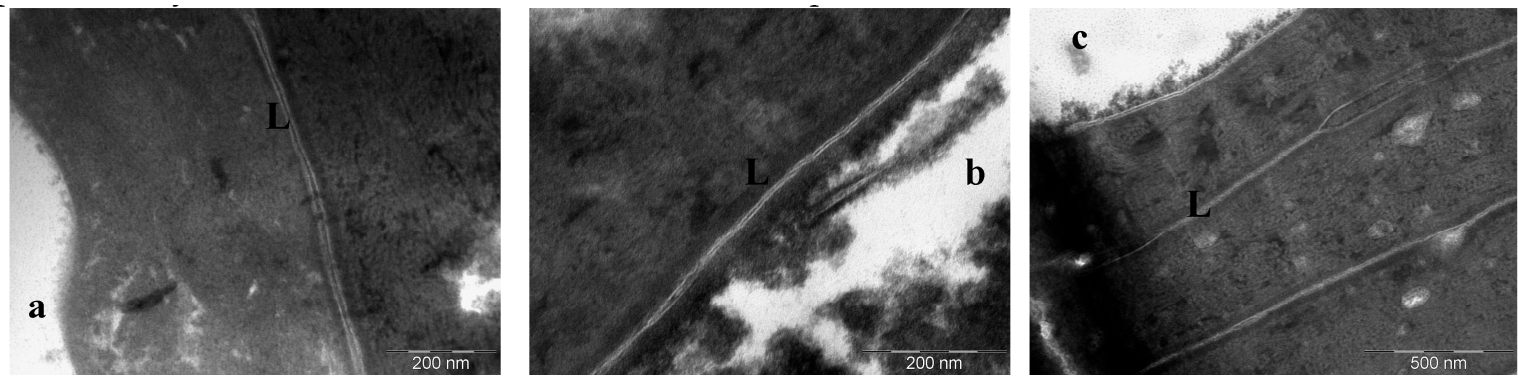

Figure 6. FSTEM micrographs for delipidized SC treated with the lipid formulations ((a) LE SC CEM; (b) LE SC IWL and (c) LE SC MIC) (L indicates the lipid region). 
Although the applied lipid formulations could give rise to an increase in the hydrophobicity of the SC sample, the obtained results could be associated with a restoration of the damaged intercellular lipid structure. Ceramide emulsion, with the higher amount of ceramide, supported the beneficial effects of the application of ceramides on damaged skin. Besides, the IWL liposome showed the importance of a suitable strategy of an accurate vehiculization for incorporating additional lipid content to reinforce the barrier function.

\section{Discussion}

It is well known that keratinized tissues, such as SC, have a common property based on their capacity to bind water. They also have a particular lipid composition with free fatty acids, cholesterol, cholesterol sulfate and ceramides. These lipids at room temperature (RT) are ordered as bilayers in a solid crystalline state and are fundamental, among other properties, in preventing water loss. In our work, SC tissues were first damaged with a known solvent system (chloroform/methanol (2:1, v:v)). This solvent system induced several changes on the SC structure, not only due to an exhaustive intercellular lipid extraction but also due to changes on the SC corneocytes. In particular, the lipid extraction led to an increase in the diffusion coefficients, demonstrating that the lipids obstructed the entrance of water molecules. The repairing capacity of lipid formulations applied on the damaged SC sample was investigated with the use of the DVS methodology. No improvement on the total water content was found, suggesting that water content diminution can be related with changes in the corneocytes water level. Modifications to the GAB energy constants seemed to indicate the presence of the lipids on the treated SC samples. However, as the GAB model was fit to data from only four RH steps, these results are not significant. When the delipidized SC was treated with the lipid formulations, the equilibration time on the DVS experiments was increased. Hence, a clear reduction of the diffusions coefficient for the lipid-treated SC samples was found, suggesting an improvement of the SC water permeability. Even though it could be related to a superficial increase in hidrophobicity due to the lipid treatments, the results suggested that probably the lipids from the different tested formulations were able to pass through the intercellular spaces of the delipidized SC and there form a lamellar organization similar to that present in the native SC. This supposition would be in concordance with previous studies where the presence of new structures was demonstrated as the result of the interaction of exogenous lipids with the lipids of the corneocyte envelope remaining in the intercellular spaces after SC delipidization [59]. However, different results have been found when comparing the three lipid mixtures. Diffusion was much reduced when LE SC was applied with the ceramide emulsion (CEM), followed by IWL liposomes and microceramides (MIC). This can be supported by the different emollient effect of each lipid formulation. Besides, the bioavailability of the lipid mixture (ceramide:cholesterol:FFA) could be higher in those formulations where the ingredients are in a soluble or liposomial form, more than dispersed as solid powder.

Irritant and sensitizing substances are known to more easily penetrate damage skin [60]. Several studies have demonstrated the importance of supplementing damaged skin, with lipids mixtures made up of the three main lipids classes present on the stratum corneum, to stimulate the functioning of the skin permeability barrier [61]. Physiologic lipids such as ceramide, cholesterol and fatty acids have shown to differ in their mechanism of action from non-physiologic lipids [62]. The composition of the applied lipids is crucial to the rate of barrier recovery. The application of an equimolar mixture of ceramide, fatty acid and cholesterol is reported to allow normal barrier recovery in mice $[63,64]$. Moreover, the depletion of physiologic lipids, especially ceramides, is a fundamental biochemical marker that accounts for increased TEWL, decreased hydration and the signs of xerotic dry skin and atopic dermatitis [24].

Our results supported all these data and demonstrated that all formulation tested were adequate for application to damaged skin in in vitro studies although some peculiar skin behavior for the three lipid formulations have been pointed out. As expected, ceramide composition, concentration and structure in the formulation produce different extents of repairing effects, in accordance with 
the bio-availability of the lipid mixture and the presence of other moisturizing ingredients in the product [65]. However, this effect was more evidenced when the applied lipids were formulated in an emulsion and as liposomes. The ceramide emulsion is a cream based on a non-ionic emulsifier that possesses high affinity and compatibility with skin [65] and, furthermore, contains the higher amount of ceramides when compared with the other formulations of this study. Moreover, the IWL liposomes, which contained less ceramides than the ceramide emulsion, also showed good skin reparation capacity that can be clearly attributed to the bilayer lipid structure of the formulation [25]. The ability of these two formulations to repair the damaged skin was confirmed by the in vivo study [65]. This work supports the use of an in vitro methodology based on the water sorption determination to evaluate skin diffusion of damaged skin and repairing formulations.

\section{Conclusions}

Moisture absorption/desorption experiments proved to be adequate for the evaluation of the repairing capacity of formulations applied on damaged skin. The three ceramide treatments evaluated act very similarly without any modification of the water absorption.

The evaluation of the times needed to reach equilibrium demonstrated that when the ceramide formulations were applied on the damaged SC, the resultant tissues needed more time to reach equilibrium. In addition, it was found that there was a clear decrease in the mean value of the apparent diffusion coefficient when the ceramide emulsion and the IWL liposomes were applied on damaged SC.

The FSTEM methodology enabled a good visualization of the lipid bilayers of the non-treated stratum corneum sample and showed an absence of lipid bilayers on the lipid-depleted SC. It can be established that the lipids formulations induced modifications in the delipidized SC. These modifications could be associated with a partial restoration of the damaged intercellular lipid structure.

The repairing capacity of three lipid formulations, containing ceramides, was followed by in vitro experiments with the use of a thermogravimetric balance. Our results support the use of an in vitro methodology based on the water sorption determination to evaluate skin diffusion of damaged skin and repairing formulations.

Acknowledgments: The authors wish to thank the Spanish National Projects (Ministerio de Educación y Ciencia) CTQ-2013-449-98-P for their financial support. The authors are indebted to the Skin Efficacy Service (SES-IQAC) for allowing the use of their non-invasive instrument techniques. The authors are grateful to Montserrat Rigol Muxart and Núria Solanes Batlló from the Department of Cardiology (Institut d'Investigacions Biomèdiques August Pi i Sunyer (IDIBAPS) Hospital Clínic, Universitat de Barcelona, Spain) for supplying porcine skin biopsies.

Author Contributions: Luisa Coderch, Alessandra Semenzatto and Giovanni Baratto designed the study, verified the results and approved the last version of the manuscript. Clara Barba and Cristina Alonso performed the experiments. Clara Barba and Luisa Coderch analyzed the results and wrote the manuscript.

Conflicts of Interest: The authors declare no conflict of interest.

\section{References}

1. Jungersted, J.M.; Hellgren, L.I.; Jemec, G.B.; Agner, T. Lipids and skin barrier function-A clinical perspective. Contact Dermat. 2008, 58, 255-262. [CrossRef] [PubMed]

2. Wartewig, S.; Neubert, R.H. Properties of ceramides and their impact on the stratum corneum structure: A review. Part 1: Ceramides. Skin Pharmacol. Physiol. 2007, 20, 220-229. [CrossRef] [PubMed]

3. Coderch, L.; Lopez, O.; de la Maza, A.; Parra, J.L. Ceramides and skin function. Am. J. Clin. Dermatol. 2003, 4, 107-129. [CrossRef] [PubMed]

4. Farwanah, H.; Raith, K.; Neubert, R.H.; Wohlrab, J. Ceramide profiles of the uninvolved skin in atopic dermatitis and psoriasis are comparable to those of healthy skin. Arch. Dermatol. Res. 2005, 296, 514-521. [CrossRef] [PubMed]

5. Scürer, N.Y. The biochemistry and function of stratum corneum lipids. Adv. Lipid Res. 1991, 24, $27-56$.

6. Elias, P.M. Lipids and the epidermal permeability barrier. Arch. Dermatol. Res. 1981, 270, 95-117. [CrossRef] [PubMed] 
7. Friegber, S.; Kayali, I.; Rhein, L.; Simion, F.A.; Cagan, R.H. The importance of lipids for water uptake in stratum corneum. Biochim. Biophys. Acta 1987, 917, 108-111.

8. Landmann, L. The epidermal permeability barrier. Anat. Embryol. 1988, 178, 1-13. [CrossRef] [PubMed]

9. Steven, A.C.; Steiner, P.M. Protein composition of cornified cell envelopes of epidermal keratinocytes. J. Cell Sci. 1994, 107, 693-700. [PubMed]

10. Groen, D.; Poole, D.S.; Gooris, G.S.; Bouwstra, J.A. Is an orthorhombic lateral packing and a proper lamellar organization important for the skin barrier function? Biochim. Biophys. Acta 2011, 1808, 1529-1537. [CrossRef] [PubMed]

11. Janůšová, B.; Zbytovská, J.; Lorenc, P.; Vavrysová, H.; Palát, K.; Hrabálek, A.; Vávrová, K. Effect of ceramide acyl chain length on skin permeability and thermotropic phase behavior of model stratum corneum lipid membranes. Biochim. Biophys. Acta 2011, 1811, 129-137. [CrossRef] [PubMed]

12. Mojumdar, E.H.; Kariman, Z.; van Kerckhove, L.; Gooris, G.S.; Bouwstra, J.A. The role of ceramide chain length distribution on the barrier properties of the skin lipid membranes. Biochim. Biophys. Acta 2014, 1838, 2473-2483. [CrossRef] [PubMed]

13. Sahle, F.F.; Gebre-Mariam, T.; Dobner, B.; Wohlrab, J.; Neubert, R.H. Skin Diseases Associated with the Depletion of Stratum Corneum Lipids and Stratum Corneum Lipid Substitution Therapy. Skin Pharmacol. Physiol. 2015, 28, 42-55. [CrossRef] [PubMed]

14. Lew, B.L.; Cho, Y.; Kim, J.; Sim, W.Y.; Kim, N.I. Ceramides and cell signaling molecules in psoriatic epidermis: reduced levels of ceramides, PKC- $\alpha$, and JNK. J. Korean Med. Sci. 2006, 21, 95-99. [CrossRef] [PubMed]

15. Farwanah, H.; Neubert, R.; Zellmer, S.; Raith, K. Improved procedure for the separation of major stratum corneum lipids by means of automated multiple development thin-layer chromatography. J. Chromatogr. B Anal. Technol. Biomed. Life Sci. 2002, 780, 443-450. [CrossRef]

16. Shikawa, J.; Narita, H.; Kondo, N.; Hotta, M.; Takagi, Y.; Masukawa, Y.; Kitahara, T.; Takema, Y.; Koyano, S.; Yamazaki, S.; et al. Changes in the ceramide profile of atopic dermatitis patients. J. Investig. Dermatol. 2010, 130, 2511-2514. [CrossRef] [PubMed]

17. Cho, Y.; Lew, B.L.; Seong, K.; Kim, N.I. An inverse relationship between ceramide synthesis and clinical severity in patients with psoriasis. J. Korean Med. Sci. 2004, 19, 859-863. [CrossRef] [PubMed]

18. Rawlings, A.; Watkinson, A.; Rogers, J.; Mayo, A.M.; Hope, J.; Scott, I.R. Abnormalities in stratum corneum structure, lipid composition, and desmosome degradation in soap-induced winter xerosis. J. Soc. Cosmet. Chem. 1994, 45, 203-220.

19. Rogers, J.; Harding, C.; Mayo, A.; Banks, J.; Rawlings, A. Stratum corneum lipids: The effect of ageing and the seasons. Arch. Dermatol. Res. 1996, 288, 765-770. [CrossRef] [PubMed]

20. Macheleidt, O.; Kaiser, H.W.; Sandhoff, K. Deficiency of epidermal protein-bound $\omega$-hydroxyceramides in atopic dermatitis. J. Investig. Dermatol. 2002, 119, 166-173. [CrossRef] [PubMed]

21. Denda, M.; Koyama, J.; Hori, J.; Horii, I.; Takahashi, M.; Hara, M.; Tagari, H. Age- and sex-dependent change in stratum corneum sphingolipids. Arch. Dermatol. Res. 1993, 285, 415-417. [CrossRef] [PubMed]

22. Imokawa, G.; Abe, A.; Jin, K.; Higaki, Y.; Kawashima, M.; Hidano, A. Decreased level of ceramides in stratum corneum of atopic dermatitis: An etiologic factor in atopic dry skin? J. Investig. Dermatol. 1991, 96, 523-526. [CrossRef] [PubMed]

23. Man, M.M.; Feingold, K.R.; Thornfeldt, C.R.; Elias, P.M. Optimization of physiological lipid mixtures for barrier repair. J. Investig. Dermatol. 1996, 106, 1096-1101.

24. Yang, L.; Mao-Qiang, M.; Taljebini, M.; Elias, P.M.; Feingold, K.R. Topical stratum corneum lipids accelerate barrier repair after tape stripping, solvent treatment and some but not all types of detergent treatment. Br. J. Dermatol. 1995, 133, 679-685. [CrossRef] [PubMed]

25. Coderch, L.; de Pera, M.; Fonollosa, J.; de La Maza, A.; Parra, J.L. Efficacy of stratum corneum lipid supplementation on human skin. Contact Dermat. 2002, 47, 139-146. [CrossRef]

26. Ramirez, R.; Marti, M.; Barba, C.; Mendez, S.; Parra, J.L.; Coderch, L. Skin efficacy of liposomes composed of internal wool lipids rich in ceramides. J. Cosmet. Sci. 2010, 61, 235-245. [CrossRef] [PubMed]

27. Sugarman, J.L.; Parish, L.C. Efficacy of a lipid-based barrier repair formulation in moderate-to-severe pediatric atopic dermatitis. J. Drugs Dermatol. 2009, 8, 1106-1111. [PubMed]

28. Draelos, Z.D. The effect of ceramide-containing skin care products on eczema resolution duration. Cutis 2008, 81, 87-91. [PubMed] 
29. Mojumdar, E.H.; Groen, D.; Gooris, G.S.; Barlow, D.J.; Lawrence, M.J.; Deme, B.; Bouwstra, J.A. Localization of cholesterol and fatty acid in a model lipid membrane: A neutron diffraction approach. Biophys. J. 2013, 105, 911-918. [CrossRef] [PubMed]

30. Jennemann, R.; Rabionet, M.; Gorgas, K.; Epstein, S.; Dalpke, A.; Rothermel, U.; Bayerle, A.; van der Hoeven, F.; Imgrund, S.; Kirsch, J.; et al. Loss of ceramide synthase 3 causes lethal skin barrier disruption. Hum. Mol. Genet. 2012, 21, 586-608. [CrossRef] [PubMed]

31. Mojumdar, E.H.; Helder, R.W.J.; Gooris, G.S.; Bouwstra, J.A. Monounsaturated Fatty Acids Reduce the Barrier of Stratum Corneum Lipid Membranes by Enhancing the Formation of a Hexagonal Lateral Packing. Langmuir 2014, 30, 6534-6543. [CrossRef] [PubMed]

32. Potts, R.O.; Francoeur, M.L. The influence of stratum corneum morphology on water permeability. J. Investig. Dermatol. 1991, 96, 495-499. [CrossRef] [PubMed]

33. Gournay, A.; Navarro, R.; Mathieu, J.; Riviere, M. Water retention of treated stratum corneum measured by a coupling method: thermal desorption-mass spectrometry. Int. J. Cosmet. Sci. 1995, 17, 165-172. [CrossRef] [PubMed]

34. Wortmann, F.; Hullmann, A.; Popescu, C. Water management of human hair. IFSCC Mag. 2007, 10, 317-320. [CrossRef]

35. Manich, A.M.; Maldonado, F.; Carilla, J.; Catalina, M.; Marsal, A. Moisture Adsorption/Desorption Kinetics of Bovine Hide Powder. J. Soc. Leather Technol. Chem. 2010, 94, 15-20.

36. Ramirez, R.; Marti, M.; Manich, A.; Parra, J.L.; Coderch, L. Ceramides Extracted from Wool: Pilot Plant Solvent Extraction. Text. Res. J. 2008, 78, 73-80. [CrossRef]

37. Semenzato, A.; Caliceti, P.; Francescato, S.; Cortese, A.C.; Baratto, G. Epidermal lipid microparticles: A new ingredient for skin care products. In Proceedings of the 26th IFSCC Congress, Buenos Aire, Argentina, 20-23 September 2010.

38. National Research Council (US) Committee for the Update of the Guide for the Care and Use of Laboratory Animals. Guide for the Care and Use of Laboratory Animals, 8th ed.; National Academies Press: Washington, DC, USA, 2011.

39. Lopez, O.; Cocera, M.; Wertz, P.M.; Lopez-Iglesias, C.; de la Maza, A. New arrangement of proteins and lipids in the stratum corneum cornified envelope. Biochim. Biophys. Acta 2007, 1768, 521-529. [CrossRef] [PubMed]

40. Barba, C.; Martí, M.; Semenzato, A.; Baratto, G.; Manich, A.M.; Coderch, L. Effect of lipid modification on stratum corneum permeability. J. Therm Anal. Calor. 2014. [CrossRef]

41. Anderson, R.B.; Hall, W.K. Modifications of the Brunauer, Emmett and Teller Equation II1. J. Am. Chem. Soc. 1948, 70, 1727-1734. [CrossRef] [PubMed]

42. Brunauer, S.; Emmett, P.H.; Teller, E. Adsorption of Gases in Multimolecular Layers. J. Am. Chem. Soc. 1938, 60, 309-319. [CrossRef]

43. Arslan, N.; Togrul, H. The fitting of various models to water sorption isotherms of tea stored in a chamber under controlled temperature and humidity. J. Stored Prod. Res. 2006, 42, 112-135. [CrossRef]

44. Vickerstaff, T. The Physical Chemistry of Dyeing; Oliver and Boid: London, UK, 1924.

45. López, O.; Cócera, M.; López-Iglesias, C.; Walter, P.; Coderch, L.; Parra, J.L.; de la Maza, A. Reconstitution of Liposomes inside the Intercellular Lipid Domain of the Stratum Corneum. Langmuir 2002, 18, 7002-7008. [CrossRef]

46. Van den Bergh, B.A.; Bouwstra, J.A.; Junginger, H.E.; Wertz, P.W. Elasticity of vesicles affects hairless mouse skin structure and permeability. J. Control. Release 1999, 62, 367-379. [CrossRef]

47. Tonon, R.; Baroni, A.; Brabet, C.; Guibert, O.; Pallet, D.; Hubinger, M. Effect of stirring on osmotic dehydration of yellow pitahaya (Selenicereus megalanthus s.). J. Food Eng. 2009, 34, 492-496.

48. Jonquières, A.; Fane, A. Modified BET models for modeling water vapor sorption in hydrophilic glassy polymers and systems deviating strongly from ideality. J. Appl. Polym. Sci. 1998, 67, 1415-1430. [CrossRef]

49. Zografi, G.; Kontny, M.J.; Yang, A.Y.S.; Brenner, G.S. Surface area and water vapor sorption of macrocrystalline cellulose. Int. J. Pharm. 1984, 18, 99-116. [CrossRef]

50. Lewicki, P.P. The applicability of the GAB model to food water sorption isotherms. Int. J. Food Sci. Technol. 1997, 32, 553-537. [CrossRef]

51. Monleon, M.; Salmeron, M.; Gallego, G.; Gomez, J.L. Thermodynamics and statistical mechanics of multilayer adsorption. J. Chem. Phys. 2004, 121, 8524-8531. [CrossRef] [PubMed] 
52. Barba, C.; Martí, M.; Manich, A.M.; Carilla, J.; Parra, J.L.; Coderch, L. Water absorption/desorption of human hair and nails. Thermochim. Acta 2010, 503-504, 33-39. [CrossRef]

53. Primavera, G.; Berardesca, E. Dynamic Measurements: The plastic occlusion stress test, moisture accumulation test, and sorption-desorption test. In Bioengineering of the Skin; Dermatology: Clinical and Basic Sciences Series; CRC Press: Boca Raton, FL, USA, 2005; Chapter 19; pp. 237-245.

54. Pilgram, G.S.; Vissers, D.C.; van der Meulen, H.; Pavel, S.; Lavrijsen, S.P.; Bouwstra, J.A.; Koerten, H.K. Aberrant lipid organization in stratum corneum of patients with atopic dermatitis and lamellar ichthyosis. J. Investig. Dermatol. 2001, 117, 710-717. [CrossRef] [PubMed]

55. Lopez, O.; Walther, P.; Cocera, M.; de La Maza, A.; Coderch, L.; Parra, J.L. Structural modifications in the stratum corneum by effect of different solubilizing agents: a study based on high-resolution low-temperature scanning electron microscopy. Skin Pharmacol. Appl. Skin Physiol. 2000, 13, 265-272. [PubMed]

56. Hofland, H.E.; Bouwstra, J.A.; Bodde, H.E.; Spies, F.; Junginger, H.E. Interactions between liposomes and human stratum corneum in vitro: Freeze fracture electron microscopical visualization and small angle $\mathrm{X}$-ray scattering studies. Br. J. Dermatol. 1995, 132, 853-866. [CrossRef] [PubMed]

57. Hofland, H.E.J.; Bouwstra, J.A.; Spies, F.; Boddé, F.E.; Nagelkerke, F.J.; Cullander, C.; Junginger, H.E. Interactions between non-ionic surfactant vesicles and human stratum corneum in vitro. J. Liposome Res. 1995, 5, 241-263. [CrossRef]

58. Van den Bergh, B.A.I.; Salomons-de Vries, I.; Bouwstra, J.A. Interactions between liposomes and human stratum corneum studied by freeze-substitution electron microscopy. Int. J. Pharm. 1998, 167, 57-67. [CrossRef]

59. López, O.; Cócera, M.; Walther, P.; Wehrli, E.; Coderch, L.; Parra, J.L.; de la Maza, A. Effect of liposomes on delipidized stratum corneum structure: An in vitro study based on high resolution low temperature scanning electron microscopy. Colloids Surf. A Physicochem. Eng. Asp. 2001, 182, 35-42. [CrossRef]

60. Berardesca, E.; Barbareschi, M.; Veraldi, S.; Pimpinelli, N. Evaluation of efficacy of a skin lipid mixture in patients with irritant contact dermatitis, allergic contact dermatitis or atopic dermatitis: A multicenter study. Contact Dermat. 2001, 45, 280-285. [CrossRef]

61. Kircik, L.H.; del Rosso, J.Q.; Aversa, D. Evaluating Clinical Use of a Ceramide-Dominant, Physiologic Lipid-Based Topical Emulsion for Atopic Dermatitis. J. Clin. Aesthet Dermatol. 2011, 4, 34-40. [PubMed]

62. Na, J.I.; Hwang, J.S.; Park, H.J.; Kim, D.H.; Park, W.S.; Youn, S.W.; Huh, C.H.; Park, K.C. A new moisturizer containing physiologic lipid granules alleviates atopic dermatitis. J. Dermatol. Treat. 2010, 21, $23-27$. [CrossRef] [PubMed]

63. Man, M.Q.; Feingold, K.R.; Elias, P.M. Exogenous lipids influence permeability barrier recovery in acetone-treated murine skin. Arch. Dermatol. 1993, 129, 728-738. [CrossRef] [PubMed]

64. Zettersten, E.M.; Ghadially, R.; Feingold, K.R.; Crumrine, D.; Elias, P.M. Optimal ratios of topical stratum corneum lipids improve barrier recovery in chronologically aged skin. J. Am. Acad. Dermatol. 1997, 37, 403-408. [CrossRef]

65. Barba, C.; Parra, J.L.; Coderch, L.; Semenzato, A. In vivo and in vitro evaluation of topical formulations containign physiological lipid mixture for replacement of skin barrier function. G Ital. Venerol. 2014, 149, 347-353.

(C) 2016 by the authors; licensee MDPI, Basel, Switzerland. This article is an open access article distributed under the terms and conditions of the Creative Commons by Attribution (CC-BY) license (http://creativecommons.org/licenses/by/4.0/). 